\title{
Cardiovascular toxicities of breast cancer treatment: emerging issues in cardio-oncology
}

\author{
Sharad Goyal ${ }^{1,2}$ * and Bruce George Haffty ${ }^{1,2}$ \\ ${ }^{1}$ Department of Radiation Oncology, Rutgers Cancer Institute of New Jersey, New Brunswick, NJ, USA \\ 2 Rutgers Robert Wood Johnson Medical School, New Brunswick, NJ, USA \\ ${ }^{*}$ Correspondence: goyalsh@rutgers.edu
}

Edited and reviewed by:

Timothy James Kinsella, Warren Alpert Medical School of Brown University, USA

Keywords: cardiovascular disease, radiation therapy, chemotherapy, breast cancer, toxicities

In 2015, the American Cancer Society estimates that 234,000 new cases of breast cancer will be diagnosed along with an additional 60,000 cases of carcinoma in situ. Nearly 40,000 women will die due to breast cancer annually (1). Current management options for Stage 0, I, \& II breast cancer include mastectomy, breast conserving surgery (BCS), or breast conserving surgery followed by whole breast radiation therapy (BCS $+\mathrm{RT})$; the use of chemotherapy is independent of local therapy. Coronary artery disease $(\mathrm{CAD})$ and cerebrovascular disease (CVD) are the first and third leading causes of death, respectively, among men and women in the United States (2). Patients with CVD share multiple common risk factors and lifestyle behaviors in addition to frequently suffering from multiple comorbid conditions. Tobacco use, hypertension, high cholesterol, diabetes, physical inactivity, and poor nutrition are all established risk factors of heart disease. The carcinogenic potential of antihypertensive medications has been widely debated and while a meta-analysis found no increase in cancer incidence or mortality, they could not rule this out with certain combinations of drugs (3). In addition, as antihypertensive medications for cardiovascular disease improve, patients are living longer and are at greater risk for developing cancer. Moreover, patients with diseases such as breast cancer may develop CVD from treatment, such as use of chemotherapy and radiation therapy (RT). Inherently within these competing risks of morbidity and mortality lays the intersection of the disciplines of cardiology and oncology.

Cardio-oncology is a relatively new field which offers an interdisciplinary and integrative management approach to cancer patients with cardiovascular risks specifically designed to mitigate risks of oncologic therapies and provide early detection and treatment of those at greatest risk of cardio-toxicity. Given the growing clinical relevance of cardio-oncology, this Frontiers in Oncology Research Topic is focused on providing information to practitioners in this quickly growing discipline. In this research topic, Mookadam et al. eloquently frames the current practice in cardio-oncology and provides future strategy and direction for this novice field.

Effects on the heart are a potentially significant and serious clinical problem in the treatment of breast cancer with RT. Over the course of the past 50 years, there have been great advances in the delivery of RT due to the development of new techniques, beam energy, improvement in imaging modalities, and development of image registration strategies. In this research topic, Yue et al. and Chen et al. present novel techniques to track cardiac motion during radiation treatments using fluoroscopy and cardiac MRI, respectively $(4,5)$. In addition, Beck et al. reviews the various radiotherapy treatment techniques used in breast cancer patients to reduce cardiac dose (6). The study reported by Merino Lara et al. attempts to translate the mean cardiac dose for various breast radiotherapy techniques to the risk of a major cardiovascular event (7). Finally, an editorial by Khan and colleagues expressively frames the debate of cardiac irradiation into perspective (8).

It is hypothesized that cardiac damage from RT is correlated to the dose absorbed by the heart and differs between left- and rightbreast radiotherapy. The damage to cardiac micro- and macrovasculature is the pathophysiological cause of RT-related heart disease. Taunk and colleagues summarize the literature regarding the underlying pathologic abnormalities and mechanisms of RT-related heart disease (9).

Other manuscripts in this issue reflect the eclectic nature of the field of cardio-oncology. Sharp and George review the potential benefit of stem cell therapy against cardio-toxicities from breast cancer treatments, while Tian et al. review the literature of serum biomarkers of cardiac toxicity after breast cancer treatments $(10,11)$. Finally, Guo and Wong discuss cardiovascular toxicities of chemotherapy and targeted therapies used in the systemic treatment of breast cancer (12).

It is our hope that through this research topic, we may continue the dialog of reducing collateral damage to the cardiovascular system by breast cancer therapies, both local and systemic. Guidelines regarding the prevention and treatment of cardiac toxicities are scant and collaborative efforts are needed to facilitate their development.

\section{REFERENCES}

1. Siegel RL, Miller KD, Jemal A. Cancer statistics, 2015. CA Cancer J Clin (2015) 65(1):5-29. doi:10.3322/caac.21254

2. Roger VL, Go AS, Lloyd-Jones DM, Adams RJ, Berry JD, Brown TM, et al. Heart disease and stroke statistics - 2011 update: a report from the American Heart Association. Circulation (2011) 123(4):e18-209. doi:10.1161/CIR. 0b013e3182009701

3. Bangalore S, Kumar S, Kjeldsen SE, Makani H, Grossman E, Wetterslev J, et al. Antihypertensive drugs and risk of cancer: network meta-analyses and trial sequential analyses of 324,168 participants from randomised trials. Lancet Oncol (2011) 12(1):65-82. doi:10.1016/S1470-2045(10)70260-6

4. Chen T, Reyhan M, Yue N, Metaxas DN, Haffty BG, Goyal S. Tagged MRI based cardiac motion modeling and toxicity evaluation in breast cancer radiotherapy. Front Oncol (2015) 5:9. doi:10.3389/fonc.2015.00009 
5. Yue NJ, Goyal S, Park JH, Jones S, Xu X, Khan A, et al. Optimization of heart block in the left-sided whole breast radiation treatments. Front Oncol (2014) 4:342. doi:10.3389/fonc.2014.00342

6. Beck RE, Kim L, Yue NJ, Haffty BG, Khan AJ, Goyal S. Treatment techniques to reduce cardiac irradiation for breast cancer patients treated with breastconserving surgery and radiation therapy: a review. Front Oncol (2014) 4:327. doi:10.3389/fonc.2014.00327

7. Merino Lara TR, Fleury E, Mashouf S, Helou J, McCann C, Ruschin M, et al. Measurement of mean cardiac dose for various breast irradiation techniques and corresponding risk of major cardiovascular event. Front Oncol (2014) 4:284. doi:10.3389/fonc.2014.00284

8. Khan AJ, Goyal S, Vicini FA. Cardiac avoidance in breast radiotherapy: many choices for a worthwhile objective. Front Oncol (2014) 4:269. doi:10.3389/fonc. 2014.00269

9. Taunk NK, Haffty BG, Kostis JB, Goyal S. Radiation-induced heart disease: pathologic abnormalities and putative mechanisms. Front Oncol (2015) 5:39. doi:10.3389/fonc. 2015.00039

10. Tian S, Hirshfield KM, Jabbour SK, Toppmeyer D, Haffty BG, Khan AJ, et al. Serum biomarkers for the detection of cardiac toxicity after chemotherapy and radiation therapy in breast cancer patients. Front Oncol (2014) 4:277. doi:10.3389/fonc. 2014.00277

11. Sharp TE III, George JC. Stem cell therapy and breast cancer treatment: review of stem cell research and potential therapeutic impact against cardiotoxicities due to breast cancer treatment. Front Oncol (2014) 4:299. doi:10.3389/fonc.2014. 00299

12. Guo S, Wong S. Cardiovascular toxicities from systemic breast cancer therapy. Front Oncol (2014) 4:346. doi:10.3389/fonc.2014.00346

Conflict of Interest Statement: The authors declare that the research was conducted in the absence of any commercial or financial relationships that could be construed as a potential conflict of interest.

Received: 03 March 2015; accepted: 03 March 2015; published online: 18 March 2015 Citation: Goyal S and Haffty BG (2015) Cardiovascular toxicities of breast cancer treatment: emerging issues in cardio-oncology. Front. Oncol. 5:66. doi: 10.3389/fonc. 2015.00066

This article was submitted to Radiation Oncology, a section of the journal Frontiers in Oncology.

Copyright (c) 2015 Goyal and Haffty. This is an open-access article distributed under the terms of the Creative Commons Attribution License (CC BY). The use, distribution or reproduction in other forums is permitted, provided the original author(s) or licensor are credited and that the original publication in this journal is cited, in accordance with accepted academic practice. No use, distribution or reproduction is permitted which does not comply with these terms. 